\title{
Capacidade institucional: uma revisão de conceitos e programas federais de governo para o fortalecimento da administração pública
}

FABIANA SILVA FERNANDES

Fundação Carlos Chagas / Departamento de Pesquisas Educacionais, SÃo PAUlo - SP, Brasil

\begin{abstract}
Resumo
Este artigo é uma revisão de conceitos sobre a capacidade institucional e de alguns programas federais implementados para fortalecer a capacidade institucional de estados, municípios e órgãos da administração pública. Para a elaboração deste trabalho, realizou-se um levantamento bibliográfico e documental sobre, respectivamente, o conceito de capacidade institucional e os programas e ações do governo federal para o fortalecimento de sua capacidade institucional. Verificou-se que o conceito tem caráter polissêmico e pragmático e foi desenvolvido para mensurar e elaborar estratégias de fortalecimento da capacidade das instituições. Da mesma forma, notou-se a existência de estreita vinculação entre capacidade institucional e capacidade de planejamento e de gestão das políticas públicas.
\end{abstract}

Palavras-chave: Capacidade institucional. Administração pública. Planejamento administrativo.

Institutional capacity: a review of concepts and federal government programs for strengthening public administration

\begin{abstract}
This article is a review of concepts on institutional capacity and some federal programs deployed to strengthen the institutional capacity of states, municipalities, and public administration bodies. For preparing this paper, a bibliographic and documentary survey was made on, respectively, the concept of institutional capacity and the programs and actions taken by the federal government to strengthen its institutional capacity. It was found that the concept has a polysemic and pragmatic nature and it was designed to measure and devise strategies to strengthen the capacity of institutions. Similarly, the existence of close ties between institutional capacity and planning and management capacity with regard to public policies was noticed.
\end{abstract}

Keywords: Institutional capacity. Public administration. Administrative planning.

La capacidad institucional: una revisión de los conceptos y programas del gobierno federal para el fortalecimiento de la administración pública

\section{Resumen}

Este artículo es una revisión de los conceptos de la capacidad institucional y algunos programas federales implementados para fortalecer la capacidad institucional de los estados, los municipios y la administración pública. Para la preparación de este trabajo, fue hecho un relevamiento de bibliografía y documentos acerca del concepto de la capacidad institucional, los programas y las acciones del gobierno federal para fortalecer su capacidad institucional. Se encontró en los textos que el concepto es polisémico y pragmático y ha sido elaborado para medir y desarrollar estrategias para fortalecer la capacidad de las instituciones. Del mismo modo, el trabajo señala que hay la existencia de una estrecha relación entre la capacidad institucional y la planificación de la capacidad y la gestión de las políticas públicas.

Palabras clave: Capacidad Institucional. Administración Pública. Planificación. 


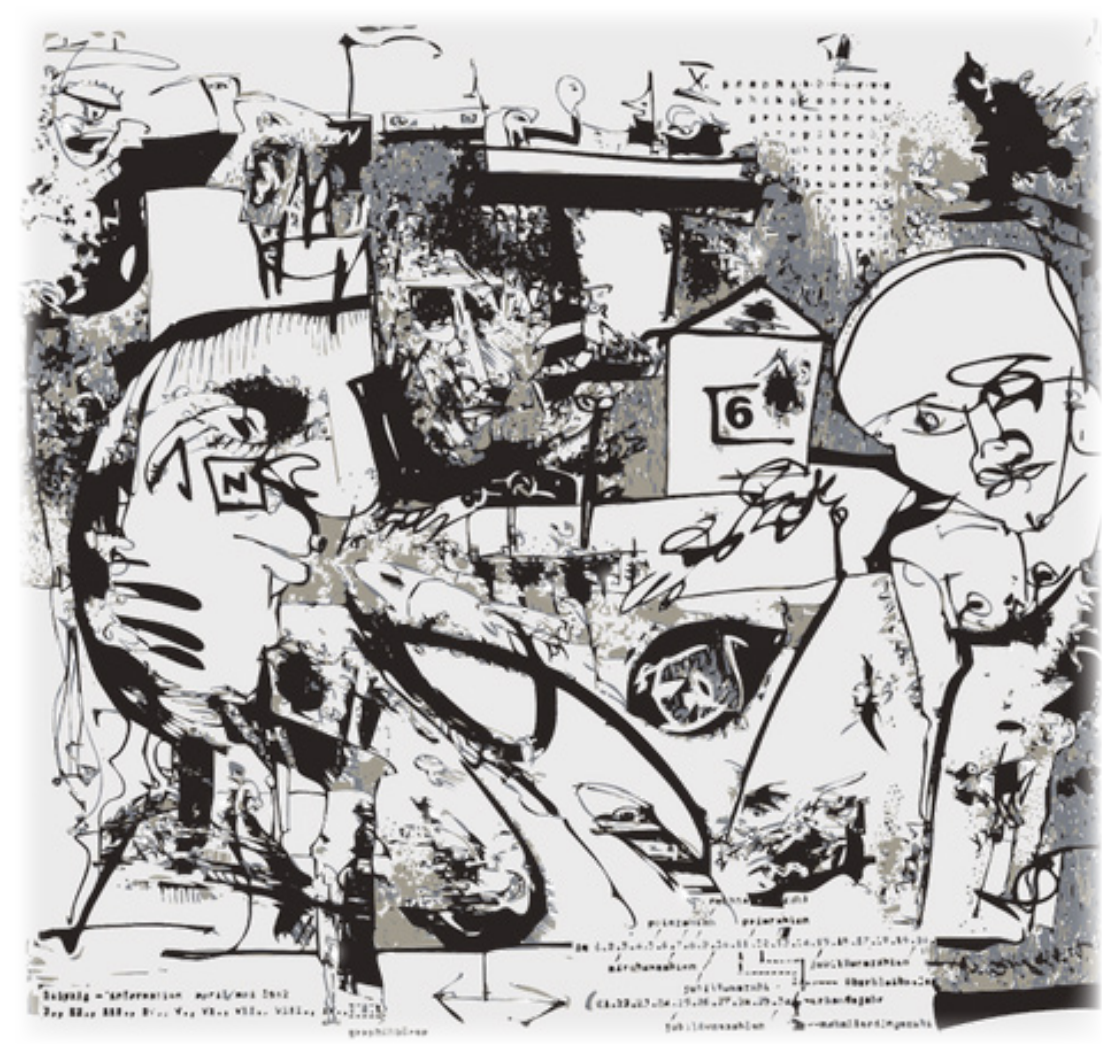

\section{INTRODUÇÃO}

No decênio de 1980, quando organismos internacionais de financiamento, principalmente o Banco Mundial, compreenderam que os empréstimos não eram investidos de forma eficiente e eficaz, porque os países em desenvolvimento não tinham capacidade de implementar suas políticas e programas, o conceito de "capacidade institucional" foi desenvolvido. Nesse período, segundo Mizrahi (2003), com a implantação de programas de aprimoramento da capacidade institucional de instituições públicas, verificou-se haver pouco incremento no setor público quanto ao desempenho de suas organizações (MARTINS e FERNANDES, 2015).

A análise desses programas, que visaram a transferir o conhecimento sobre a capacidade institucional dos países desenvolvidos para os em desenvolvimento, permitiu a construção de um novo referencial sobre aprimoramento de competências institucionais, levando em consideração as capacidades locais existentes. Esse contexto desencadeou um movimento de países e organismos internacionais em torno da avaliação das condições institucionais existentes para a implementação dos serviços públicos, estimulando o surgimento de organizações públicas e privadas especializadas na avaliação de capacidade e implementação de programas de aprimoramento da capacidade institucional.

No Brasil, verificou-se a existência de programas federais de fortalecimento da capacidade institucional de estados e municípios, conforme apresentado adiante, embora não se tenha notado, ainda, grande visibilidade dessas iniciativas. É provável que esse seja um dos motivos pelos quais os estudos sobre a capacidade institucional no país ainda se restrinjam a setores da administração pública, havendo parca literatura acadêmica, fato observado no levantamento bibliográfico sobre o tema.

* Fonte da imagem: Openclipart- Imagem vetorial de desenho a lápis artística. 
Este trabalho objetiva revisar conceitos de capacidade institucional e sintetizar algumas ações do governo federal para o fortalecimento da capacidade institucional de estados e municípios, bem como de órgãos da administração pública, desenvolvidas na década de 2000.

Para a elaboração deste trabalho, foi feito um levantamento bibliográfico e documental sobre, respectivamente, o conceito de capacidade institucional e os programas e ações do governo federal brasileiro. Foram consultados sites do Banco Internacional de Reconstrução e Desenvolvimento (Bird, também denominado Banco Mundial), Banco Interamericano de Desenvolvimento (BID), Programa das Nações Unidas para o Desenvolvimento (PNUD), Conselho Nacional de Secretários de Estado da Administração (Consad); sites de governos e organizações que prestam assessoria na área de administração, identificadas com base em consulta nas páginas mencionadas. Também foram consultadas páginas oficiais do governo brasileiro, principalmente do Ministério do Planejamento, Orçamento e Gestão (MP), por meio do qual se obteve informações sobre programas de governo para o desenvolvimento da capacidade institucional da administração pública federal e dos entes federativo.

Este artigo não pretende esgotar referências sobre capacidade institucional, mesmo porque são restritas, limitando-se a abordar referências que discutem especificamente esse conceito, excluindo-se autores que debatem a capacidade de governo, governança e governabilidade. $O$ texto sintetiza um esforço de revisão conceitual feito em pesquisa na Fundação Carlos Chagas $(F C C)^{1}$, que encontrou lacunas no desenvolvimento de referências analíticas sobre a capacidade institucional que subsidiassem a pesquisa.

Os programas de governo foram objeto desta reflexão conceitual também e, portanto, buscou-se descrevê-los de forma a identificar como essa capacidade institucional era compreendida nos documentos normativos e planos de ação.

\section{CAPACIDADE INSTITUCIONAL: CONCEITOS E DEFINIÇÕES ${ }^{2}$}

Como dito anteriormente, a capacidade institucional tem sido objeto de atenção de organismos internacionais e governos. Os trabalhos acadêmicos que discutem a referida noção tratam indiretamente da capacidade, tendo como referência experiências implantadas do setor público para discutir as possibilidades e limites de entes federativos e setores da administração pública para implementar políticas e oferecer seus serviços. Não foram encontrados, no Brasil, trabalhos de pesquisa que se debruçassem sobre o conceito de capacidade institucional como referência de análise para a produção de conhecimento e desenvolvimento de metodologias de pesquisa.

Segundo Vidal (2013), os estudos sobre capacidade institucional enfocam a análise do aparato burocrático do Estado ou a qualidade da regulação das agências reguladoras, sendo ainda recentes e escassos os estudos direcionados a outras esferas da administração pública, como os municípios.

Mizhahi (2003) fez um levantamento da literatura sobre o conceito de capacidade institucional e metodologias de avaliação ligadas a programas e projetos de intervenção desenvolvidos por organismos multilaterais e agências de assessoria.

Lessik e Michener (2000), em Measuring institutional capacity, apresentam várias propostas de avaliação da capacidade institucional, cuja finalidade é medir a capacidade de uma organização, ou de seus componentes individuais ou suas funções.

O trabalho enfoca, fundamentalmente, organizações privadas e do terceiro setor, propondo um conjunto de reflexões provenientes das assessorias conduzidas pelos gestores da Agência dos Estados Unidos para o Desenvolvimento Internacional (USAID, em inglês, United States Agency for International Development). A experiência de trabalho da agência permitiu-lhe observar que a capacidade institucional das organizações que contratam seus serviços está diretamente relacionada aos

\footnotetext{
${ }^{1}$ Este artigo resulta do trabalho de revisão bibliográfica feita pela autora no âmbito da pesquisa intitulada "A capacidade institucional de municípios: uma análise de políticas educacionais em regiões metropolitanas", financiada pela FCC e pela Fundação de Amparo à Pesquisa do Estado de São Paulo (Fapesp) e coordenada por Angela Maria Martins. Do estudo participaram: Gláucia Novaes, Jéssica Munhoz Araújo, Cláudia Pimenta Oliveira, Cleiton de Oliveira e Pedro Ganzeli. Foram consultoras: Joana Buarque Gusmão e Valéria Virgínia Lopes. O estudo-piloto foi realizado em 10 municípios localizados nas três regiões metropolitanas de São Paulo, com vistas a construir indicadores de gestão da educação municipal que possibilitassem analisar a capacidade desses municípios de implementar suas políticas educacionais.

${ }^{2}$ A revisão conceitual sobre capacidade institucional foi abordada em uma comunicação oral feita pela autora e por Angela Maria Martins, no 270 Simpósio Brasileiro de Política e Administração da Educação, realizado em Olinda-PE, em abril de 2015.
} 
alcances dos resultados da organização, o que sugere a necessidade de investimento e fortalecimento dessa capacidade organizacional, para além do assessoramento para a implementação de programas que viabilizem os objetivos das organizações. Para isso, é necessário, primeiro, mediar a capacidade institucional, procedimento que orienta as intervenções necessárias nas organizações. Nesse sentido, as autoras apresentam várias ferramentas e metodologias de avaliação de capacidade institucional, empregadas pelos técnicos da USAID e cuja seleção depende do tipo de organização e do contexto da avaliação.

Um aspecto interessante do trabalho diz respeito à discussão do termo capacidade institucional (institutional capacity), sobre o qual as autoras afirmam se tratar do mesmo conjunto de problemas que os termos "construção institucional" (institution building), "fortalecimento institucional" (institutional strengthening), "capacidade organizacional" (organizational capacity) e "desenvolvimento organizacional" (organizational development). Nesse sentido, no texto, esses termos são usados de forma intercambiável.

Mizrahi (2003), em revisão bibliográfica sobre a operacionalização dos conceitos de "capacidade" e "aprimoramento de capacidade" (capacity enhancement), identifica indicadores de capacidade e reforço de capacidade na literatura sobre o tema, bem como as dificuldades e os desafios da mensuração do reforço de capacidade.

A autora constata a falta de consenso em torno da identificação e mensuração do reforço de capacidade, chegando a algumas conclusões importantes sobre o quadro teórico e a operacionalização do conceito:

- o reforço da capacidade envolve algo a mais que o fortalecimento de habilidades individuais;

- o reforço da capacidade é um processo e, portanto, pode ser mensurado em graus que requerem a definição de quadros referenciais;

- os indicadores de desempenho (performance indicators) não podem ser substituídos por indicadores de reforço de capacidade (capacity enhancement indicators);

- enquanto o reforço da capacidade pode ser medido em três dimensões analíticas (institucional, organizacional e individual), os indicadores de reforço não podem ser construídos no abstrato, pois os "indicadores somente são operacionalizados quando eles estão relacionados com objetivos específicos de desenvolvimento (capacidade para quê?) e fazem referências aos atores para os quais o reforço da capacidade é direcionado (capacidade para quem?)" (MIZRAHI, 2003, p. VI, tradução nossa).

Para a autora, a capacidade institucional e organizacional não se limita a habilidades individuais, adotando uma definição mais ampla de capacidade, em que outras dimensões da instituição ou da organização possam ser inseridas em um quadro de referência que analise a capacidade ou busque o reforço da capacidade: a institucional e a organizacional.

Em relação ao conceito de reforço de capacidade, há uma dimensão temporal, que permite defini-lo como um processo cujo caráter operacional requer o estabelecimento de algumas referências de análise ao longo de um período de tempo contínuo. Além disso, o reforço deve conduzir diferentes graus de capacidade, envolvendo um processo complexo de aprendizado, adaptação e mudança de atitudes nos níveis institucional, organizacional e individual (MIZRAHI, 2003, p. 4). Essas qualidades do conceito geraram, em grande parte, as dificuldades de mensuração do reforço de capacidade, uma vez que, por ser processo, não diz respeito ao resultado final (a final outcome), ou a um rendimento (output), mais fáceis de quantificar. Nesse sentido, o foco das análises tem sido a mensuração do desempenho (performance), pois é mais fácil identificar os indicadores de desempenho e as experiências em torno da operacionalização do reforço de capacidade não têm sido bem-sucedidas.

Já a operacionalização dos conceitos de capacidade e de reforço da capacidade e a identificação de ferramentas de medição e definição de indicadores tem sido marcada por propostas vagas e abstratas. Embora a autora apresente alguns quadros analíticos que se propõem a analisar o reforço das capacidades e mostre algumas ferramentas e técnicas usadas na elaboração dos indicadores de capacidade institucional, identifica, nas propostas analisadas, a falta de metodologia para organizar uma análise mais sistemática da capacidade institucional. Além disso, os indicadores são vagos e servem mais como um quadro global orientador, ainda que tenham permitido compreender que capacidade e reforço de capacidade devem ser abordados em três níveis de análise: o individual (habilidades humanas), o organizacional e o institucional. Por último, a autora sugere quadros analíticos para o desenvolvimento de indicadores de reforço de capacidade. 
Taylor (2010) apresenta cinco dimensões possíveis de intervenção para a construção da capacidade institucional: construção do conhecimento base da organização (building the knowledge base), por meio do qual é possível a obtenção de um melhor entendimento dos objetivos, propósitos e formas de ação da organização; desenvolvimento profissional (professional development), relacionados à formação dos recursos humanos; fortalecimento organizacional (organisational strengthening); que envolve os níveis intraorganizacional e interorganizacional; reformas diretivas (directive reforms); e reformas que estimulam mudanças na organização (facilitative reforms), todas relacionadas às leis e políticas desenvolvidas no âmbito governamental.

\section{PROGRAMAS E AÇÕES DO GOVERNO FEDERAL BRASILEIRA COM VISTA AO FORTALECIMENTO DA CAPACIDADE INSTITUCIONAL DA ADMINISTRAÇÃO PÚBLICA}

A capacidade institucional dos governos subnacionais, no Brasil, passou a ser objeto de atenção na década de 2000 . Daí em diante, primeiro por iniciativa do governo federal, vêm se desenvolvendo ações e programas cujos propósitos são a avaliação e o fortalecimento da capacidade institucional dos entes subnacionais, em especial dos municípios. Ao mesmo tempo, desenvolve uma série de estudos e reflexões no âmbito da administração pública sobre experiências realizadas em torno de projetos de fortalecimento institucional nos municípios brasileiros.

Lubambo (2002), ao apresentar o processo de instalação e a atuação das comissões municipais de emprego, do Programa Estadual de Qualificação (PEQ), em Pernambuco, compreende os conselhos gestores tendo como pressuposto a ideia de que os atores das referidas esferas de participação são corresponsáveis por sua implementação.

Os conselhos gestores, como mecanismos de controle social, constituem um traço do perfil político-institucional dos municípios e sua atuação é um dos fatores que determinam o desempenho da gestão municipal, estando, portanto, relacionados à capacidade institucional dos municípios para implementar os serviços públicos (LUBAMBO, 2012).

Definindo a capacidade institucional de uma instância administrativa como um conjunto de organizações capazes de empreender ações públicas descentralizadas e efetivas, Lubambo (2012) afirma que essa é condição garantidora da continuidade do desempenho, da estrutura e dos processos instituídos das unidades federativas. Para a elaboração do conceito, a autora adota como procedimento a aproximação de capacidade institucional com o tema da governabilidade, governabilidade essa relacionada à qualidade da gestão pública e ao conjunto de estratégias de gestão social que garantam a eficácia das decisões e a efetividade das ações adotadas, promovendo a aceitação social das políticas implementadas. Nesse sentido, poder-se-ia afirmar a existência de uma relação proporcional entre governabilidade e capacidade institucional em que, quanto maior o grau de governabilidade, maior a capacidade institucional dos governos de implementar suas políticas.

Veloso, Monasterio, Vieira et al. (2011) em pesquisa empírica que procura diagnosticar a gestão pública municipal brasileira com o propósito de, entre outros, identificar os entraves a seu fortalecimento institucional não discutem o conceito, mas reconhecem que a capacidade institucional está relacionada à governabilidade, à transparência e à eficácia da ação pública municipal. Os autores discorrem sobre a capacidade de gestão pública, que se aproxima da compreensão que Lubambo (2012) expressa sobre a capacidade institucional:

[...] a capacidade de gestão pública pode ser definida e descrita de diversas formas, mas basicamente consiste na habilidade das administrações de cumprir suas responsabilidades em um governo democrático: i) utilizar sabiamente os recursos públicos e direcioná-los para os objetivos desejados; ii) gerir programas e pessoas de forma eficiente; iii) avaliar se os objetivos estão sendo alcançados (VELOSO, MONASTERIO, VIEIRA et al., 2011, p. 19).

Para a realização do trabalho, Veloso, Monasterio, Vieira et al. (2011) selecionaram municípios de portes diferentes, de sete estados brasileiros, das regiões Norte, Nordeste, Sul e Sudeste e avaliaram as seguintes dimensões: gestão financeira, gestão de capital e infraestrutura, gestão de pessoas e gestão de tecnologias da informação (TI), constatando que a gestão financeira, em $50 \%$ dos municípios, tem um aporte institucional considerável, aspecto que contribui para a estabilidade das atribuições e atividades do setor, mesmo em tempos de mudança política e administrativa, o que não acontece com as demais dimensões da administração pública municipal. 
Quanto à gestão de capital e de infraestrutura destaca-se a baixa escolaridade dos funcionários desse setor:

No Pará, 70\% dos envolvidos têm até o nível fundamental. Mesmo nas prefeituras do Rio de Janeiro e do Paraná, que em outras áreas possuem indicadores razoáveis de escolaridade, na área sob escopo os indicadores apresentam mão de obra pouco qualificada (VELOSO, MONASTERIO, VIEIRA et al., 2011, p. 28).

Já o gerenciamento de recursos humanos é marcado pela ampla disparidade entre os municípios: pouco mais de 1/3 dos municípios grandes conta com uma secretaria exclusiva para a gestão de pessoas e não há um padrão regional claro, uma vez que estados tão diferentes como São Paulo e Alagoas têm uma baixa parcela de municípios dotados de secretarias exclusivas para a gestão de recursos humanos.

Chama a atenção o vínculo empregatício dos funcionários, uma vez que há um contraste entre municípios grandes e pequenos: enquanto estes têm 54\% dos funcionários estatutários e 11\% em cargos comissionados, naqueles esses percentuais chegam a 70\% e 6\%, respectivamente (Veloso, Monasterio, Vieira et al., 2011).

Por fim, a gestão de TI raramente conta com uma secretaria exclusiva e é nessa área que a terceirização é mais intensa.

Nota-se, portanto, que o trabalho coordenado por Veloso (2011) apresenta um diagnóstico importante que aponta fragilidades institucionais dos municípios e indica um caminho metodológico relevante para que pesquisas sobre capacidade institucional sejam desenvolvidas no Brasil, em especial a dos municípios, cuja estrutura organizacional é marcada por disparidades regionais, falta de aporte institucional que garanta o planejamento adequado das ações e o emprego de recursos humanos bem formados e a falta de eficiência, eficácia e transparência nos processos da administração pública municipal. Ações têm sido implementadas para fortalecer a capacidade institucional da administração pública direta e de municípios, mas os esforços de avaliação da capacidade municipal são importantes para que os programas e as ações se fundamentem nas fragilidades e nas dificuldades concretas.

Cruz, Montoro e Bio (2011b) apresentam os principais resultados da pesquisa "Fortalecimento institucional e qualificação da gestão municipal no estado de São Paulo", fundamentando-se no conceito de capacidade institucional, definido como "habilidade das administrações [para] cumprirem suas responsabilidades em um governo democrático: utilizar bem os recursos públicos e direcioná-los para os objetivos desejados; gerir programas e pessoas de forma eficiente, e avaliar se os objetivos estão sendo alcançados" (CRUZ, MONTORO e BIO, 2011b, p. 3). Esse estudo parece ser um dos primeiros a se ocupar das investigações sobre a capacidade institucional dos municípios, permitindo um diagnóstico da capacidade de gestão das administrações públicas, mediante a identificação de elementos pertencentes à estrutura administrativa das prefeituras e relacionados ao desempenho das políticas públicas de forma geral.

A capacidade institucional do Poder Público municipal para Cruz, Montoro, Bio et al. (2011a, p. 89) está relacionada à capacidade de formulação e implementação das políticas públicas e, para que seja fortalecida, os autores reconhecem a necessidade da existência de unidade administrativa na estrutura organizacional, para garantir a "continuidade das atribuições e das atividades em períodos de mudanças política e administrativa".

Lofrano (2010) esclarece a preocupação do governo federal com a capacidade de implementação e execução das políticas sociais, em congresso realizado pelo Consad. Fundamentando-se no pacto federativo brasileiro, que proporcionou aos entes subnacionais autonomia administrativa e status político semelhante ao da União, o autor discorre sobre as dificuldades que os municípios têm enfrentado para exercer suas funções de planejamento, gestão, monitoramento e avaliação de políticas públicas, o que justificaria os esforços da União para melhorar a capacidade institucional dos municípios.

Um dado importante apresentado no trabalho foi a formação de um Grupo de Trabalho para o Fortalecimento Institucional e Qualificação da Gestão dos Municípios, instituído pelo Comitê de Articulação Federativa (CAF). Iniciando seus trabalhos em agosto de 2007, o grupo tinha por propósito o "estabelecimento de conceitos comuns no que tange os referenciais de capacidade de gestão municipal, capacitação e assistência técnica, tecnologia da informação, simplificação do acesso aos programas federais e cidadania, controle e participação social..." (LOFRANO, 2010, p. 6). Além disso, a intenção era que o grupo subsidiasse os ministérios e demais órgãos federais na capacitação, apoio e fortalecimento da gestão municipal dos municípios, com prioridade para os de pequeno porte. 
O Consad parece ter tido importância também nas orientações à administração pública sobre o desenvolvimento da capacidade institucional. Constituído em 2000, como entidade privada, o Consad é um órgão permanente de coordenação e articulação dos interesses das Secretarias de Administração, que tem por finalidade propor políticas públicas no âmbito de atuação das Secretarias e participar do processo de formulação e implementação das políticas nacionais para o setor. Os encontros periódicos promovidos pelo órgão, no Congresso Consad de Gestão Pública têm sido um mecanismo de divulgação de experiências, metodologias e propostas de fortalecimento institucional.

\section{PROGRAMAS E AÇÕES DO GOVERNO FEDERAL PARA O FORTALECIMENTO DA CAPACIDADE INSTITUCIONAL}

No âmbito do governo federal, o fortalecimento da capacidade institucional da administração pública federal direta, das autarquias e das fundações tem sido objeto de preocupação e foi normatizada pelo Decreto n. 6.944, de 21/08/2009. 0 art. 1 ㅇ desse decreto define o fortalecimento da capacidade institucional como

[...] o conjunto de medidas que propiciem aos órgãos ou entidades da administração pública federal direta, autárquica e fundacional a melhoria das suas condições de funcionamento, compreendendo as de caráter organizacional, que lhes proporcionem melhor desempenho no exercício de suas competências institucionais, especialmente na execução dos programas do Plano Plurianual - PPA (BRASIL, 2009).

Além disso, o decreto criou o Sistema de Organização e Inovação Institucional (Siorg), cuja atribuição é organizar as atividades de desenvolvimento organizacional dos órgãos e entidades da administração direta, autárquica e fundacional do Poder Público federal com as finalidades de, entre outras, constituir rede colaborativa voltada à melhoria da gestão pública e proporcionar meios para melhorar o desempenho institucional e otimizar o emprego dos recursos disponíveis.

Em 12/01/2010 foi publicada a Instrução Normativa n. 3, que dispõe sobre o processamento de propostas de fortalecimento da capacidade institucional dos órgãos ou entidades da administração pública federal direta, autárquica e fundacional. Por meio dessa instrução, a Secretaria de Gestão do MP normatizou o envio das demandas de fortalecimento da capacidade institucional dos órgãos e das entidades, cujas propostas de fortalecimento passariam por um processo de seleção e seriam divulgadas no site eletrônico da Secretaria de Gestão do MP.

A Secretaria de Gestão Pública (Segep) foi criada por meio do Decreto n. 7.675, publicado no Diário Oficial da União em 23/01/2012. Resultado da fusão entre a Secretaria de Gestão (Seges) e parte da Secretaria de Recursos Humanos (SRH), a Segep promoveu a revisão da estrutura regimentar do MP e, entre as várias competências dos órgãos, podem ser destacadas também as atividades relacionadas ao fortalecimento da capacidade institucional no âmbito da administração pública federal. No art. 23 do decreto de criação da Segep, entre as competências definidas para o setor, relacionadas à gestão dos recursos humanos, estão a pactuação de resultados e sistemas de incentivos e de avaliação de desempenho e o aperfeiçoamento e a inovação da gestão dos órgãos e entidades da administração pública federal, aspectos relacionados com a capacidade institucional.

Entre os sete departamentos que compõem a Secretaria de Gestão Pública encontram-se o Departamento de Inovação e Melhoria da Gestão e o Departamento do Desenvolvimento de Desempenho Institucional. Ao primeiro, de acordo com o art. 24 do Decreto n. 7.675, de 2012, compete, entre suas várias atribuições, propor políticas e diretrizes de gestão pública que visem ao fortalecimento da governança das instituições públicas; promover a realização de estudos e pesquisas que ampliem o conhecimento em gestão pública e gerem subsídios para a tomada de decisão governamental, propor medidas e executar ações para o fortalecimento e o aperfeiçoamento da gestão de processos no âmbito da administração pública federal; fomentar e apoiar ações e projetos de cooperação técnica e financeira em gestão pública, inclusive em nível internacional.

Ao Departamento de Desenvolvimento e Desempenho Institucional, no art. 26 do referido decreto, estabeleceu-se, entre as várias atribuições do setor, as competências para propor políticas e diretrizes relativas à gestão por resultados, o estabelecimento de metas de desempenho institucional e de sistemas de incentivos e de avaliação de resultados; e a fixação de metas de desempenho institucional, como contratos de desempenho. 
Cabe destacar que a atuação do governo federal não se limitou a procurar estratégias para o fortalecimento da capacidade institucional da administração pública federal, estendendo essa preocupação para os demais níveis de governo. Antes mesmo da publicação do Decreto n. 6.944, de 2009, que normatiza o fortalecimento da capacidade institucional da administração pública federal direta, em 2005 foi elaborado o Programa Nacional de Apoio à Modernização da Gestão e do Planejamento dos Estados e do Distrito Federal (PNAGE), com apoio do BID. Com duração de cinco anos, o programa tinha por objetivos, entre outros, fortalecer a capacidade de planejamento e de gestão dos estados e desenvolver a capacidade institucional para a administração de recursos humanos.

As ações previstas foram atividades de capacitação e assistência técnica para fortalecer a coordenação entre as áreas de planejamento, administração e finanças, buscando, também, introduzir novos modelos de gestão de recursos humanos e TI. A expressão "capacidade institucional", nesse programa, parece não se constituir um referencial orientador, embora esteja presente como conceito que integra as dimensões instituição, organização e recursos humanos, nos componentes e subcomponentes do programa:

1. fortalecimento da capacidade de planejamento e de gestão de políticas públicas;

2. desenvolvimento de políticas e da capacidade de gestão de recursos humanos;

3. modernização de estruturas organizacionais e de processos administrativos;

4. fortalecimento dos mecanismos de transparência administrativa e de comunicação;

5. modernização da gestão de informações e integração dos sistemas de TI; e

6. desenvolvimento de uma cultura de promoção e implantação de mudança institucional.

Em relação aos municípios, o Projeto Brasil Municípios - Reforço da Capacidade Institucional em Municípios selecionados para a Redução da Pobreza, lançado em 2009, foi elaborado para promover o desenvolvimento institucional e o fortalecimento da gestão. O projeto, sob responsabilidade da Secretaria de Gestão, consiste em uma cooperação técnica entre governo federal e a União Europeia, tendo o BID como agente executor de ações, e cujo objetivo é fortalecer as capacidades das administrações municipais para o planejamento, a gestão, a avaliação e o monitoramento de políticas públicas e programas e projetos governamentais nas regiões Norte e Nordeste do Brasil ${ }^{3}$. Entre as atividades desenvolvidas no projeto, destacam-se a realização de estudos, a promoção de ações de desenvolvimento institucional (capacitação e assistência técnica) e o estímulo a parcerias intermunicipais, envolvendo consórcios, redes e outras formas de associativismo.

Outro projeto, iniciado em 2008 e concluído em 2014, foi o da Modernização da Gestão Pública (disponível em http://www. planejamento.gov.br/secretaria.asp?cat=401\&sec=54), firmado entre o MP do Brasil e a Agência Espanhola de Cooperação Internacional para o Desenvolvimento (Aecid). O projeto, coordenado pela Seges, objetiva proporcionar a modernização da gestão pública brasileira. As ações do projeto são organizadas segundo estes eixos temáticos: fortalecimento das capacidades institucionais da Seges; melhoria dos processos e instrumentos de interlocução do MP com a administração pública federal; melhoria dos processos e instrumentos de interlocução do MP com atores de cooperação e colaboração (entes federados, Organização Social (OS), Organização da Sociedade Civil de Interesse Público (Oscip), Organizações Não Governamentais (ONG) etc.); e sistematização e divulgação de experiências bem-sucedidas e lições aprendidas. Da execução do projeto participam, além do MP, a Secretaria Geral da Presidência da República, municípios, ONG e diversas instituições públicas, como universidades e fundações. Um dos produtos desse projeto foi a elaboração de um guia referencial para a medição do desempenho da gestão e a proposta para o gerenciamento dos indicadores de eficiência, eficácia e de resultados do Programa Nacional de Gestão Pública e Desburocratização (Gespública). Esse guia, parte de um relatório organizado em cinco partes, enfoca a construção de indicadores de desempenho, constituindo um referencial metodológico para os governos e a administração pública em geral.

No âmbito do Ministério da Fazenda também foi desenvolvido um projeto, em 2004, com financiamento do BID, cujo propósito era o fortalecimento institucional dos órgãos responsáveis pela gestão administrativa e fiscal dos municípios brasileiros. Para a realização do programa estava previsto o apoio à implantação de projetos de fortalecimento institucional que considerassem os seguintes aspectos: um modelo gerencialista de gestão, com foco nos clientes e voltado para resultados; uma

\footnotetext{
As informações sobre o projeto "Brasil Municípios" foram obtidas em consultas realizadas na internet, nas páginas do Ministério do Planejamento, do Projeto Brasil e do Banco Interamericano de Desenvolvimento. Para mais informações, consultar os sites: <http://www.planejamento.gov.br> e $<$ http://www.projetobrasilmunicipios.gov.br>. Nas consultas aos sites, não foi possível saber se o projeto ainda está em vigor. Entretanto, foram encontrados outros projetos que atuam no reforço ou desenvolvimento da capacidade institucional, implementados em conjunto, o Pró-Cidades, em que a participação do município foi um dos critérios para selecionar os entes federativos a ser contemplados no projeto "Brasil Municípios", e o "Modernização da Gestão Pública".
} 
política de recursos transparente e abrangente de recursos humanos, dimensionando um quadro de pessoal condizente com as necessidades concretas da administração pública municipal; métodos e instrumentos de planejamento; controle e monitoramento da programação de execução orçamentária e financeira; novas técnicas e metodologias de arrecadação, fiscalização e cobrança administrativa (disponível em http://www.planejamento.gov.br/secretaria.asp?cat=401\&sec=54).

Nota-se que, nos programas apresentados, o conceito de capacidade institucional está relacionado à capacidade de planejamento e de gestão das políticas públicas e seu desenvolvimento ou fortalecimento envolve a garantia de atendimento da demanda efetiva e a racionalização dos processos administrativos e financeiros, de modo a garantir a eficiência dos serviços prestados. Nesse sentido, "capacidade institucional" é um termo bastante polissêmico, articulado a uma concepção gerencial de administração pública, na medida em que os esforços para o desenvolvimento e o fortalecimento da gestão municipal têm como focos a modernização, a transparência, o controle social e o foco nos resultados.

O vínculo entre a capacidade institucional e o modelo administrativo parece ter a influência das orientações do BID, uma vez que o banco é o maior financiador dos programas voltados ao problema em questão e os desenhos dos programas implementados pelo organismo envolvem um modelo de gestão por resultados. No 62o Fórum do Consad, realizado em Florianópolis, Faria (2008), vinculado ao BID, apresentou, como temas estratégicos, adotados como orientações para o financiamento de programas, entre os vários temas, estes: modernização dos sistemas de gestão e gestão por resultados; qualidade do gasto público e gestão de investimentos; melhoria na prestação dos serviços públicos; gestão e desenvolvimento do capital humano; planejamento da força de trabalho, gestão do desempenho e desenvolvimento gerencial e construção de capacidade institucional para a gestão de investimentos: marco institucional e capacidade técnica para análise econômica, elaboração e execução de projetos ${ }^{4}$.

\section{CONSIDERAÇÕES FINAIS}

A primeira observação sobre as referências encontradas foi a de que a capacidade institucional é uma preocupação de governos e de agências públicas e privadas que desenvolvem programas de fortalecimento da capacidade institucional. No caso brasileiro, setores e agências da administração pública do governo federal, principalmente a Secretaria de Gestão, formularam programas de fortalecimento da capacidade institucional e manifestaram a intenção de prestar assessoria técnica a estados e municípios.

A segunda é sobre a própria noção de capacidade institucional, de caráter polissêmico e pragmático, referindo-se, nos programas de governo mencionados, à estrutura e aos processos organizacionais e administrativos de instituições públicas, que deveriam viabilizar o cumprimento de objetivos e metas estabelecidos pelas organizações.

Em terceiro lugar, o conceito de capacidade institucional foi desenvolvido para subsidiar estratégias de medição dessa capacidade, fundamentalmente de setores e órgãos de governo, de modo que projetos de intervenção fossem elaborados para a remoção de obstáculos e para seu fortalecimento institucional. Isso significa que capacidade institucional envolve a identificação dos objetivos e metas da instituição com o propósito de aprimorá-la ou reforçá-la. Para tanto, parece haver consenso entre os autores consultados de que compreender a capacidade institucional de uma organização exige a definição da dimensão sobre a qual a capacidade se refere, buscando responder às seguintes questões: Capacidade para quê? Capacidade para quem? Esse deveria ser o ponto de partida de um projeto de avaliação de capacidade: identificar as dimensões de análise, nos planos institucional, organizacional e de recursos humanos, seguidas dos indicadores e de sua forma de operacionalização.

No caso dos programas de governo implementados com o propósito de fortalecer a capacidade institucional de entes federativos e setores da administração pública, parece haver estreito vínculo entre capacidade institucional e capacidade de planejamento e de gestão das políticas públicas pela racionalização dos processos administrativos, modernização dos sistemas de informação, estabelecimento de relações com atores de cooperação e colaboração, entre outros aspectos explicitados quando da análise dos programas implantados pelo governo federal, que remetem aos componentes organizacionais mencionados por Lessik e Michener (2000), nas diferentes propostas de avaliação institucional observadas pelos autores, quais sejam: funções administrativas e de suporte, funções técnicas/programas, estrutura e cultura e recursos.

\footnotetext{
${ }^{4}$ As informações divulgadas por Faria (2008) referem-se à palestra ministrada pelo autor e estão disponíveis em slides de apresentação no site do Consad <http://www.consad.org.br/> (cf. sessão "Palestras").
} 


\section{REFERÊNCIAS}

BRASIL. Decreto n. 6.944, de 21 de agosto de 2009. Estabelece medidas organizacionais para o aprimoramento da administração pública federal direta, autárquica e fundacional, dispõe sobre normas gerais relativas a concursos públicos, organiza sob a forma de sistema as atividades de organização e inovação institucional do Governo Federal, e dá outras providências. Diário Oficial da União, 24 ago. 2009. Seção 1. Disponível em: <http://www.planalto.gov. br/ccivil_03/_Ato2007-2010/2009/Decreto/D6944.htm>. Acesso em: 15 ago. 2012.

BRASIL. Instrução Normativa n³, de 12 de janeiro de 2010. Diário Oficial [da] República Federativa do Brasil, Poder Executivo, Brasília, DF, 13 jan., 2010. Seção 1. 46 p.

BRASIL. Decreto n. 7.675, 23 e janeiro de 2012. Diário Oficial [da] República Federativa do Brasil, Poder Executivo, Brasília, DF, 23 jan., 2012. Seção 1.2 p.

CRUZ, M. C. M. T. et al. Gestão pública no estado de São Paulo: elementos para um olhar analítico. In: VELOSO, J. F. A. et al. (Orgs.). Gestão municipal no Brasil: um retrato das prefeituras. Brasília, DF: Ipea, 2011a. 87-140 p.

CRUZ, M. C. M. T.; MONTORO, F. A. F.; BIO, S. R. Reflexões sobre a capacidade de gestão paulista: análise das gestões financeira, de capital e infraestrutura, de pessoas e de tecnologia da informação. In: CONGRESSO CONSAD DE GESTÃO PÚBLICA, 4., Brasília, 2001. [s.n]. Brasília, DF: Consad, 2011b.

FARIA, P. A ação do BID no apoio à modernização da gestão pública no Brasil. In: FÓRUM DO CONSAD, 72., Florianópolis, 2008. [s.n]. Florianópolis: Consad, 2008.
LESSIK, A.; MICHENER, V. Measuring institutional capacity. Washington, DC: International Development Cooperation Agency/United States Agency for International Development, 2000. 1-25 p. (Recent Practices in Monitoring and Evaluation Tips, n. 15).

LOFRANO, R. Mecanismos de desenvolvimento institucional: programas de apoio aos municípios. In: CONGRESSO CONSAD DE GESTÃO PÚBLICA, 3., Brasília, 2010. [s.n]. Brasília, DF: Consad, 2010.

LUBAMBO, C. W. Conselhos gestores e desempenho da gestão nos municípios: potencialidades e limites. Textos para Discussão: TPD, n. 149, 2002. Disponível em: <http://periodicos.fundaj.gov.br/TPD/ article/view/944/665>. Acesso em: 15 ago. 2011.

MARTINS, A. M.; FERNANDES, F. S. Capacidade institucional: concepções e referenciais de análise. In: SIMPÓSIO BRASILEIRO DE POLÍTICA E ADMINISTRAÇÃO DA EDUCAÇÃO, 27, Olinda, 2015. Anais... Olinda, PE: AnPAE, 2015. 1-12 p. 1 CD-ROM.

MIZRAHI, Y. Capacity enhancement indicator: review of the literature. Washington, DC: World Bank Institute, 2003. Disponível em: <http://info.worldbank.org/etools/docs/library/80314/EG03-72. pdf>. Acesso em: 15 ago. 2012.

TAYLOR, A. Model background briefing notes. Sidney: CMA Sydney Metropolitan/New South Waler Government, 2010.

VELOSO, J. F. A. et al. Uma visão inicial dos subsistemas da gestão pública municipal. In: VELOSO, J. F. A. et al (Orgs.). Gestão municipal no Brasil: um retrato das prefeituras. Brasília, DF: Ipea, 2011. 11-40 p.

VIDAL, J. P. Uma observação autorreferencial na Defensoria Pública do Estado do Pará. Amazônia, Organizações e Sustentabilidade, v. 2, n. 1, p. 85-98, 2013. 